\title{
Estaquia de Ginkgo biloba L. utilizando três substratos
}

\author{
BITENCOURT, J.; ZUFFELLATO-RIBAS, K.C.*; KOEHLER, H.S. \\ Universidade Federal do Paraná (UFPR), CEP: 81531-970, Curitiba-Brasil *kazu@ufpr.br
}

\begin{abstract}
RESUMO: Ginkgo biloba é arbórea, decídua, cuja folhagem se torna amarelada no outono antes da queda das folhas, o que a torna valorizada em jardinagem. A estaquia é um método de propagação vegetativa baseado na capacidade das células em retomarem o processo de divisão celular, formando raízes em estacas destacadas de ramos provenientes de plantas matrizes. $O$ presente trabalho teve como objetivos verificar a influência de diferentes substratos, assim como, a aplicação da auxina sintética o ácido indol butírico (AIB) no enraizamento de estacas de Ginkgo biloba. No inverno de 2005, ramos foram coletados e transportados até o Laboratório de Macropropagação, onde foram confeccionadas estacas sem folhas, com 10-12 cm de comprimento. Os tratamentos com regulador vegetal (T) foram T1- $0 \mathrm{mg} \mathrm{L}^{-1}$ AlB em solução; T2$4000 \mathrm{mg} \mathrm{L}^{-1}$ AIB em solução; T3- $8000 \mathrm{mg} \mathrm{L}^{-1}$ AIB em solução; T4- 0 mg kg-1 AIB em talco; T5$4000 \mathrm{mg} \mathrm{kg}^{-1} \mathrm{AlB}$ em talco e T6- $8000 \mathrm{mg} \mathrm{kg}^{-1} \mathrm{AlB}$ em talco. Para cada tratamento foram utilizados três diferentes substratos (S), S1- areia, S2- fibra de casca de coco (coxim) e S3- casca de arroz carbonizada. Após 120 dias da instalação, foram avaliadas as porcentagens de estacas enraizadas, vivas, com calos e mortas; o número de raízes por estaca e o comprimento das três maiores raízes por estaca. Os melhores resultados no enraizamento foram obtidos com estacas tratadas com 4000 e $8000 \mathrm{mg} \mathrm{kg}^{-1}$ AIB em talco, utilizando o coxim como substrato $(45,00$ e $46,25 \%$ de enraizamento, respectivamente).
\end{abstract}

Palavras-chave: enraizamento, areia, coxim, casca-de-arroz carbonizada, auxinas

ABSTRACT: Ginkgo biloba L. cutting using three substrates. Ginkgo biloba is an arboreal and deciduous species, the foliage of which becomes yellowish in the autumn, before leaf drop, increasing its value for gardening. Cutting is a method of vegetative propagation based on the capacity of cells to recover the cell division process, originating roots in cuttings detached from branches of stock plants. This study aimed to verify the influence of different substrates, as well as the application of the synthetic auxin indole-3-butyric acid (IBA) in Ginkgo biloba cutting rooting. In the winter of 2005, branches were collected and sent to the Macropropagation Lab, where cuttings of $10-12 \mathrm{~cm}$ length were made without leaves. The treatments with plant growth regulator (T) were T1- $0 \mathrm{mg} \mathrm{L}^{-1}$ IBA solution, T2- $4000 \mathrm{mg} \mathrm{L}^{-1}$ IBA solution, T3- $8000 \mathrm{mg} \mathrm{L}^{-1}$ IBA solution, T4- $0 \mathrm{mg} \mathrm{kg}^{-1}$ IBA in talc, T5- $4000 \mathrm{mg} \mathrm{kg}^{-1}$ IBA in talc, T6- $8000 \mathrm{mg} \mathrm{kg}^{-1}$ IBA in talc. Each treatment was planted in three substrates (S), S1- sand, S2- coir and S3- carbonized rice hull. After 120 days, the percentages of cuttings that were rooted, alive, with callus and dead were evaluated, besides the number of roots per cutting and the length of the three highest roots per cutting. The best results regarding rooting were obtained for cuttings treated with 4000 and 8000 $\mathrm{mg} \mathrm{kg}^{-1}$ IBA in talc, by using coir as substrate (45.00 and $46.25 \%$ rooting, respectively).

Key words: rooting, sand, coir, carbonized rice hull, auxins

\section{INTRODUÇÃO}

Ginkgo biloba é árvore de grande porte, caducifólia, dióica, de folhas simples, agrupadas em ramos laterais, com lâmina em forma de leque e nervação dicotômica. O cultivo é ideal para clima temperado e o principal atrativo ornamental é a coloração amarelada das folhas no outono que caem com a chegada do inverno. Além disso, é amplamente comercializada como medicinal, sendo utilizada no tratamento de disfunções geriátricas, como perda de memória e problemas arteriais (Backes \& Irgang, 2004).

Recebido para publicação em 11/05/2008

Aceito para publicação em 08/03/10

Rev. Bras. PI. Med., Botucatu, v.12, n.2, p.135-140, 2010. 
Por ser dióica, a produção de mudas por sementes necessita de exemplares dos dois sexos, o que pode dificultar a reprodução da espécie. Além disso, segundo Acharya et al. (2001), há registros de exemplares na Índia com mais de 55 anos de idade que nunca entraram em estado reprodutivo, tornando o lento desenvolvimento da espécie mais um empecilho para a produção de mudas por meio de sementes.

A estaquia é a técnica de propagação vegetativa mais utilizada na produção de mudas e visa a formação de raízes adventícias nas estacas (Hartmann et al., 2002), que podem se formar a partir de grupos de células já maduras de caules e folhas que entram no ciclo de divisão celular (Kerbauy, 2004).

O ácido indol butírico (AIB) e o ácido naftaleno acético (ANA) são auxinas sintéticas que podem estimular o enraizamento de estacas (Alvarenga \& Carvalho, 1983). Essas substâncias podem ser aplicadas na base das estacas na forma de talco ou solução. A aplicação na forma líquida é mais uniforme e por isso pode resultar em dados mais consistentes (Dole \& Wilkins, 1999).

O substrato, isto é, o meio onde as raízes se desenvolvem (Kämpf, 2000), deve ser poroso, bem drenado, homogêneo, livre de patógenos, ter baixa densidade e viabilidade econômica. O material deve permitir que a base da estaca obtenha bom suprimento de água e ao mesmo tempo oxigênio, uma vez que a deficiência de $\mathrm{O}_{2}$ causa a paralisação do crescimento das raízes. Quanto maior a quantidade de matéria orgânica no substrato, pior é a drenagem do mesmo e maior é a capacidade de retenção de água (Edmond et al., 1957; Moraes et al., 2001; Wendling et al., 2002).

$\mathrm{Na}$ estaquia de espécies de difícil enraizamento, o substrato é um dos fatores de maior importância, mas a fertilidade não é fator determinante na escolha, uma vez que são utilizadas as reservas da estaca na formação das raízes (Wendling et al., 2002).

Em trabalho com estaquia de Ginkgo biloba, Chiang et al. (1996) encontraram diferenças significativas na porcentagem de enraizamento para diferentes substratos, porém não entre diferentes concentrações de AIB. No mesmo trabalho, foram encontradas diferenças entre os substratos e aplicação de AIB para a variável número de raízes por estaca e diferenças significativas no comprimento das raízes formadas para as diferentes concentrações de AIB, mas não em relação aos diferentes substratos.

Sendo assim, este trabalho teve como objetivos verificar a influência de diferentes substratos no enraizamento de estacas caulinares de Ginkgo biloba, assim como, a aplicação do regulador vegetal ácido indol butírico (AIB) nas formas de talco e solução, em diferentes concentrações.

\section{MATERIAL E MÉTODO}

O presente trabalho foi conduzido na casade-vegetação do Laboratório de Macropropagação do Departamento de Botânica da Universidade Federal do Paraná, Curitiba-PR, entre os meses de junho e outubro de 2005. As estacas foram obtidas a partir de ramos de Gingko biloba provenientes de plantas matrizes com sete anos de idade pertencentes à empresa Chamel, em Campo Largo - PR.

A coleta foi realizada no período da manhã e os ramos foram umedecidos, acondicionados em sacos plásticos e transportados para o Laboratório onde foram colocados em baldes com água para evitar a desidratação até o término da confecção das estacas.

As estacas foram confeccionadas sem folhas, com corte em bisel na região basal do ramo e corte reto acima da última gema lateral, mantendoas com aproximadamente 10 a $12 \mathrm{~cm}$ de comprimento e 0,4 a $1,0 \mathrm{~cm}$ de diâmetro em média. Depois de prontas, as estacas foram desinfestadas em solução de hipoclorito de sódio a 0,5\% por 15 minutos, sendo em seguida lavadas em água corrente. Posteriormente, os tratamentos foram aplicados às bases das estacas, tendo T1- $0 \mathrm{mg} \mathrm{L}^{-1} \mathrm{AIB}$ (solução $50 \%$ alcoólica); T2- $4000 \mathrm{mg} \mathrm{L}^{-1}$ AIB (solução $50 \%$ alcoólica); T3- $8000 \mathrm{mg} \mathrm{L}^{-1}$ AIB (solução 50\% alcoólica); T4- $0 \mathrm{mg} \mathrm{kg}^{-1}$ AlB em talco; T5- $4000 \mathrm{mg}$ $\mathrm{kg}^{-1}$ AIB em talco; T6- $8000 \mathrm{mg} \mathrm{kg}^{-1}$ AIB em talco. O tempo de imersão das estacas na solução foi de 10 segundos e o AIB utilizado foi P.A.

A areia foi colocada em caixas plásticas com furos no fundo para evitar o acúmulo de água, enquanto a fibra da casca de coco (coxim) e a casca de arroz carbonizada foram colocadas em tubetes de polipropileno com capacidade de $53 \mathrm{~cm}^{3}$. As estacas foram mantidas em casa de vegetação com nebulização de cinco minutos de duração, programada por timer três vezes ao dia (8, 13 e 17h).

Após 120 dias da instalação do experimento foram avaliadas as porcentagem de estacas enraizadas, consideradas aquelas com raízes a partir de $1 \mathrm{~mm}$ de comprimento; número de raízes por estaca; comprimento das três maiores raízes por estaca (em mm); porcentagem de estacas com calos, consideradas aquelas vivas, com formação de calos e sem formação de raízes; porcentagem de estacas vivas, consideradas aquelas vivas, sem formação de calos nem raízes e porcentagem de estacas mortas.

Os dados foram analisados segundo delineamento inteiramente casualizado, com arranjo fatorial de seis tratamentos e três substratos $(6 \times 3)$ e quatro repetições de 20 estacas por unidade experimental. Os dados obtidos foram submetidos à análise de variância. Inicialmente, as variâncias dos tratamentos foram avaliadas quanto a sua homogeneidade pelo teste de Bartlett. As variáveis

Rev. Bras. PI. Med., Botucatu, v.12, n.2, p.135-140, 2010. 
cujas variâncias mostraram-se homogêneas tiveram as médias testadas pelo teste de $F$, enquanto as que apresentaram heterogeneidade tiveram os valores originais transformados para posterior análise. Quando os resultados revelaram existir diferenças significativas entre as médias dos tratamentos, estas foram comparadas pelo teste de Tukey a $5 \%$ de probabilidade.

\section{RESULTADO E DISCUSSÃO}

Os resultados obtidos na análise de variância estão apresentados na Tabela 1 e pode-se observar que todas as variáveis apresentaram variâncias homogêneas.

Para a porcentagem de estacas enraizadas houve interação significativa entre os dois fatores analisados (Tabela 1). As maiores médias foram observadas nos tratamentos veiculados em talco, com 4000 e $8000 \mathrm{mg} \mathrm{kg}^{-1}$ AIB, no substrato coxim (45,00 e 46,25\%, respectivamente) e $4000 \mathrm{mg} \mathrm{kg}^{-1}$ AIB no substrato casca de arroz carbonizada (29,17\%) (Tabela 2). Considerando a porcentagem de estacas enraizadas, em cada tratamento nos três substratos, as respostas de enraizamento não diferiram estatisticamente entre si nas concentrações de 0 , 4000 e $8000 \mathrm{mg} \mathrm{L}^{-1}$ AIB em solução. Quando o veículo usado foi o talco, observaram-se percentagens de enraizamento maiores no substrato coxim, em todas as concentrações com relação à areia e, no tratamento com 8000 mg kg-1 AIB com relação à casca de arroz carbonizada. Pela superioridade na promoção do enraizamento, o coxim foi o substrato mais favorável ao enraizamento de Ginkgo biloba.

Pode-se observar na Tabela 2, que quando se utiliza o AIB em solução, não há diferença entre os substratos para porcentagem de estacas enraizadas. Porém, quando se utiliza talco como veículo de aplicação do IBA, as diferenças aparecem, de modo que o coxim é superior à areia para todas as concentrações de AIB testadas e à casca de arroz carbonizada para a concentração de $8000 \mathrm{mg} \mathrm{kg}^{-1}$. A areia e casca de arroz carbonizada não diferem estatisticamente entre si, para os tratamentos em talco.

Utilizando a areia como substrato, o tratamento com $8000 \mathrm{mg} \mathrm{L}^{-1}$ AIB foi o que apresentou a maior porcentagem de enraizamento $(31,25 \%)$, apesar de não mostrar diferença estatística dos demais tratamentos, exceto quando comparado a 0 $\mathrm{mg} \mathrm{kg}^{-1} \mathrm{AIB}$, que apresentou a menor porcentagem de enraizamento (2,50\%). Com a casca de arroz carbonizada, os tratamentos com AIB não apresentaram diferença estatística entre si. Já com o substrato coxim, os melhores resultados foram obtidos com a utilização de AIB em talco, nas

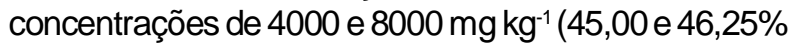
de enraizamento, respectivamente), os quais diferiram estatisticamente dos demais tratamentos.

Em experimento com Acacia mearnsii, Borges Junior \& Martins-Corder (2002) observaram que a concentração de $2000 \mathrm{mg} \mathrm{L}^{-1}$ de AIB em talco

TABELA 1. Resultados da análise de variância para a porcentagem de estacas de Ginkgo biloba enraizadas, número de raízes por estaca, comprimento médio das três maiores raízes por estaca e porcentagem de estacas vivas, com calos e mortas, para os seis tratamentos com regulador vegetal e três substratos.

\begin{tabular}{|c|c|c|c|c|c|c|c|}
\hline \multirow[b]{2}{*}{ Fator de Variação } & \multirow[b]{2}{*}{ G.L. } & \multicolumn{6}{|c|}{ Quadrado médio } \\
\hline & & $\begin{array}{c}\text { Estacas } \\
\text { enraizadas } \\
(\%)\end{array}$ & $\begin{array}{l}\mathrm{N}^{\circ} \text { de } \\
\text { raízes por } \\
\text { estaca }\end{array}$ & $\begin{array}{c}\text { Comp. } 3 \text { > } \\
\text { raízes } \\
(\mathrm{mm})\end{array}$ & $\begin{array}{c}\text { Estacas } \\
\text { vivas } \\
(\%)\end{array}$ & $\begin{array}{c}\text { Estacas } \\
\text { com calos } \\
(\%)\end{array}$ & $\begin{array}{c}\text { Estacas } \\
\text { mortas } \\
(\%)\end{array}$ \\
\hline Tratamentos (T) & 5 & $643,087^{*}$ & $6,661^{*}$ & $64,615^{\star}$ & $3277,834^{*}$ & $421,801^{\text {ns }}$ & $675,276^{*}$ \\
\hline Substratos (S) & 2 & $883,533^{*}$ & $1,085^{\mathrm{ns}}$ & $139,976^{*}$ & $2914,370^{*}$ & $3574,477^{*}$ & $1198,201^{*}$ \\
\hline$T \times S$ & 10 & $368,068^{*}$ & $1,150^{*}$ & $25,666^{*}$ & $97,044^{\mathrm{ns}}$ & $223,139^{\text {ns }}$ & $171,822^{*}$ \\
\hline Erro & 54 & 119,785 & 0,344 & 8,629 & 177,479 & 219,891 & 35,899 \\
\hline Total & 71 & & & & & & \\
\hline C. V. $(\%)$ & & 52,55 & 29,66 & 38,79 & 42,41 & 43,74 & 43,24 \\
\hline Teste de Bartlett $\left(\chi^{2}\right)$ & & $17,204^{\mathrm{ns}}$ & $16,186^{\mathrm{ns}}$ & $21,752^{\mathrm{ns}}$ & $21,397^{\mathrm{ns}}$ & $13,607^{\mathrm{ns}}$ & $13,520^{\mathrm{ns}}$ \\
\hline
\end{tabular}

* Significativo a $5 \%$ de probabilidade ${ }^{\text {ns }}$ Não significativo a $5 \%$ de probabilidade 
TABELA 2. Resultados do teste de comparação de médias para porcentagem de estacas de Ginkgo biloba enraizadas, provenientes da interação dos seis tratamentos com regulador vegetal e dos três substratos.

\begin{tabular}{|c|c|c|c|c|c|c|c|c|c|}
\hline \multirow[b]{3}{*}{$0 \mathrm{mg} \mathrm{L}^{-1}$} & \multicolumn{9}{|c|}{ Estacas enraizadas (\%) } \\
\hline & \multicolumn{3}{|c|}{ Areia } & \multicolumn{3}{|c|}{ Coxim } & \multicolumn{3}{|c|}{$\begin{array}{c}\text { Casca de arroz } \\
\text { carbonizada }\end{array}$} \\
\hline & 10,00 & $a b$ & A & 18,75 & c & $A$ & 15,28 & a & $A$ \\
\hline $4000 \mathrm{mg} \mathrm{L}^{-1}$ & 18,75 & $a b$ & $A$ & 18,75 & c & $A$ & 15,28 & a & $A$ \\
\hline $8000 \mathrm{mg} \mathrm{L}^{-1}$ & 31,25 & $\mathrm{a}$ & $A$ & 15,00 & c & A & 25,00 & a & $A$ \\
\hline $0 \mathrm{mg} \mathrm{kg}^{-1}$ & 2,50 & $\mathrm{~b}$ & B & 22,50 & $\mathrm{bc}$ & A & 9,73 & a & $A B$ \\
\hline $4000 \mathrm{mg} \mathrm{kg}^{-1}$ & 15,00 & $a b$ & B & 45,00 & $a b$ & A & 29,17 & a & $A B$ \\
\hline $8000 \mathrm{mg} \mathrm{kg}^{-1}$ & 20,00 & $a b$ & B & 46,25 & a & A & 16,67 & $a$ & B \\
\hline
\end{tabular}

Médias seguidas da mesma letra minúscula na vertical, para tratamentos com AIB, e médias seguidas da mesma letra maiúscula na horizontal, para substratos, não diferem significativamente pelo teste de Tukey a $5 \%$ de probabilidade. Concentrações indicadas em mg $\mathrm{L}^{-1}$ se referem aos tratamentos em solução e concentrações indicadas em $\mathrm{mg} \mathrm{kg}^{-1}$ se referem aos tratamentos em talco.

foi a que promoveu a maior porcentagem de estacas enraizadas $(69,2 \%)$, enquanto os outros tratamentos não diferiram estatisticamente entre si e a concentração de $8000 \mathrm{mg} \mathrm{L}^{-1}$ de AIB em talco inibiu a formação de raízes nas estacas $(27,5 \%$ de estacas enraizadas). No mesmo trabalho, outro experimento realizado com a mesma espécie não apresentou diferença estatística para a porcentagem de estacas enraizadas, entre tratamentos com as concentrações de AIB em talco de 500, 1000, 1500 e $2000 \mathrm{mg} \mathrm{kg}^{-1}$. Estes resultados diferem do presente trabalho, onde a aplicação de AIB juntamente com a utilização do coxim como substrato, otimizaram o enraizamento das estacas.

Acharya et al. (2001), em experimento com Ginkgo biloba, observaram que o melhor substrato para o enraizamento desta espécie foi uma composição de solo com $\mathrm{pH}$ ácido. No presente trabalho, os melhores resultados no enraizamento foram obtido com o coxim, que segundo Dole \& Wilkins (1999) é um substrato de pH ácido (de 4,5 a 6,9).

Pimenta (2003) comparou o enraizamento de Sapium glandulatum em vermiculita e casca de arroz carbonizada, observando que a última é mais eficiente na primavera, embora a porcentagem de enraizamento tenha sido baixa $(4,2 \%)$.

Para o número de raízes por estaca, houve interação entre os dois fatores analisados (Tabela 1) e o teste de comparação de médias mostra que não houve diferença entre os substratos para os tratamentos em solução (Tabela 3). Já para os tratamentos em talco, o coxim apresentou os melhores resultados em relação à areia nas concentrações de 0 e $8000 \mathrm{mg} \mathrm{kg}^{-1}$. Não foram observadas diferenças significativas entre o coxim e a casca de arroz carbonizada, enquanto a areia foi superior à casca de arroz carbonizada na concentração de $4000 \mathrm{mg} \mathrm{kg}^{-1}$ de AIB.

Utilizando a areia como substrato, os tratamentos com 4000 e $8000 \mathrm{mg} \mathrm{kg}^{-1} / \mathrm{mg} \mathrm{L}^{-1}$ de AIB em talco ou solução foram os que apresentaram os maiores números de raízes. Já com o coxim e a casca de arroz carbonizada, os melhores resultados foram obtidos com 4000 e $8000 \mathrm{mg} \mathrm{kg}^{-1}$ de AIB em talco. $O$ número de raízes por estaca é fator importante a ser considerado, uma vez que mudas com sistema radicial vigoroso terão maiores chances de sobrevivência quando transplantadas para o campo (Reis et al., 2000).

Para o comprimento das três maiores raízes por estaca, houve interação entre os dois fatores analisados (Tabela 1). De maneira geral, quando comparados os três substratos, a areia e o coxim apresentaram os maiores valores. Utilizando a areia como substrato, os melhores resultados foram obtidos com AIB nas concentrações de 4000 e $8000 \mathrm{mg} \mathrm{L}^{-1}$ em solução e $4000 \mathrm{mg} \mathrm{kg}^{-1} \mathrm{em}$ talco. Utilizando o coxim como substrato, o tratamento com $8000 \mathrm{mg}$ $\mathrm{kg}^{-1} \mathrm{em}$ talco foi superior apenas ao tratamento $0 \mathrm{mg}$ $\mathrm{L}^{-1}$ em solução, enquanto na casca de arroz carbonizada não foram observadas diferenças entre os tratamentos (Tabela 3).

Valmorbida \& Lessa (2005), utilizando areia como substrato, obtiveram até $80,55 \%$ de enraizamento em estaquia de Ginkgo biloba, com comprimento médio das raízes de $17,8 \mathrm{~mm}$. No presente trabalho, a maior média de comprimento das raízes $(15,97 \mathrm{~mm})$ foi observada no tratamento com $8000 \mathrm{mg} \mathrm{L}^{-1} \mathrm{AIB}$, utilizando areia como substrato.

Quanto às variáveis, porcentagem de estacas vivas e com calos, não foi observada interação entre os fatores analisados (Tabela 1). Os tratamentos com 4000 e $8000 \mathrm{mg} \mathrm{kg}^{-1}$ AIB em talco foram os que 


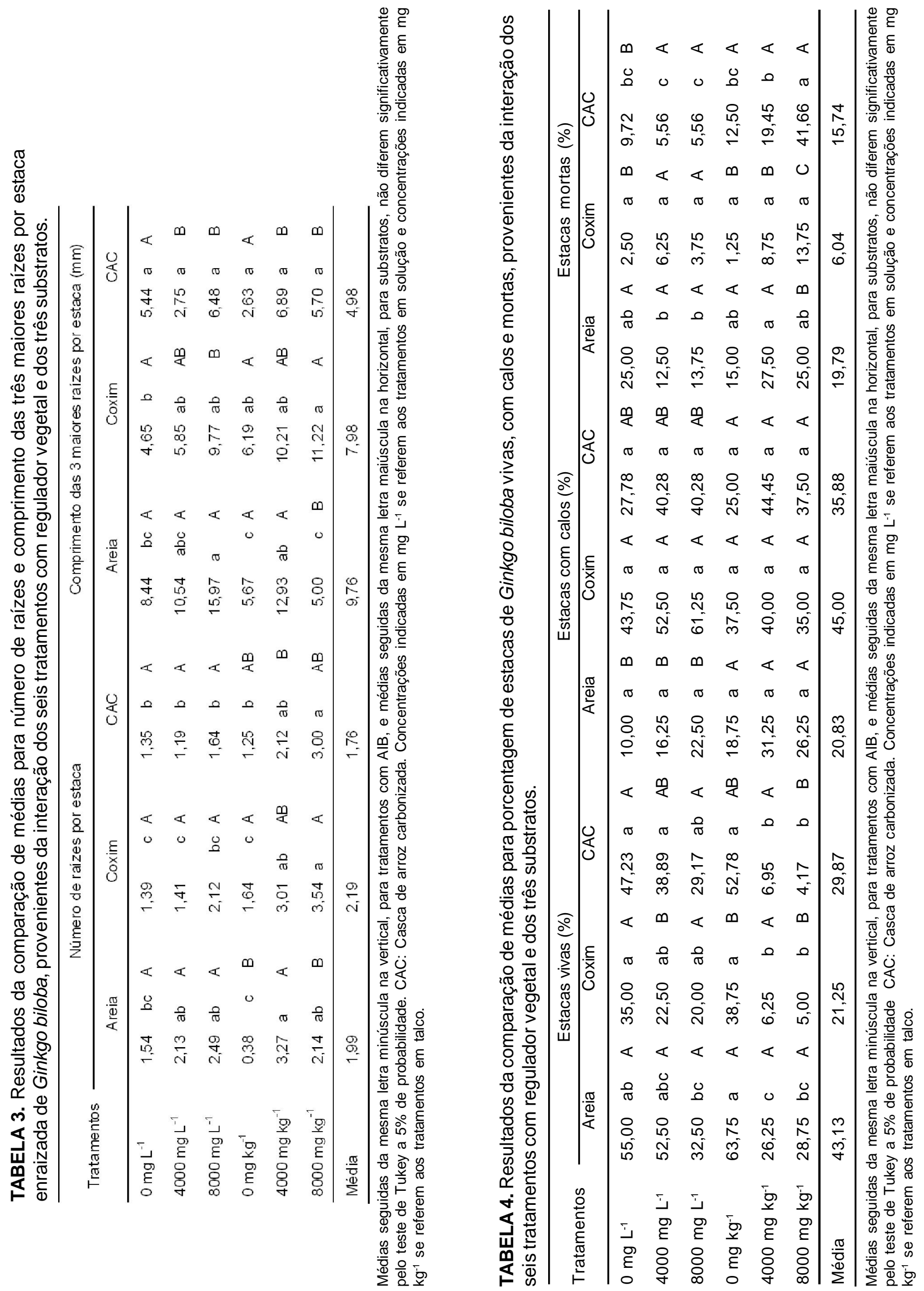

Rev. Bras. PI. Med., Botucatu, v.12, n.2, p.135-140, 2010. 
apresentaram as menores porcentagens de estacas vivas em cada substrato utilizado.

A formação de calos foi influenciada pelos substratos, mas não pelos tratamentos com AIB e o coxim apresentou tendência maior à formação de calos, apesar de não diferir estatisticamente da cascade-arroz carbonizada em nenhum dos tratamentos. Foi observada diferença entre coxim e areia nos tratamentos em solução (Tabela 4). No momento da avaliação, foi observado que grande parte das estacas enraizadas apresentou formação de calos, o que poderia ser indicativo de enraizamento futuro, já que, segundo Hamann (1998), naquelas espécies consideradas de difícil enraizamento geralmente há formação de calos precedendo a formação de raízes. Desta forma, se as estacas fossem deixadas por mais tempo na casa-de-vegetação, talvez pudesse ter sido observada a formação de raízes.

Para porcentagem de estacas mortas, a análise de variância mostrou que há interação entre os fatores estudados (Tabela 1). Nas concentrações de 4000 e $8000 \mathrm{mg} \mathrm{L}^{-1} \mathrm{AIB}$, não houve diferença significativa entre os substratos, enquanto nos demais tratamentos, o coxim apresentou as menores taxas de mortalidade, diferindo estatisticamente dos demais, exceto no tratamento com $0 \mathrm{mg} \mathrm{L}^{-1} \mathrm{AIB}$ (Tabela 4).

\section{AGRADECIMENTO}

Os autores agradecem ao Sr. Estefano Dranka, proprietário da Empresa Chamel, em Campo Largo - PR, por ter disponibilizado o material vegetal para a realização deste trabalho.

\section{CONCLUSÃO}

Nas condições em que foi realizado o experimento, pode-se concluir que a aplicação de 4000 ou $8000 \mathrm{mg} \mathrm{kg}^{-1}$ AIB em talco, utilizando o substrato coxim, aumenta a porcentagem de enraizamento de estacas de Ginkgo biloba.

\section{REFERÊNCIA}

ACHARYA, M. et al. Ginkgo propagation by simple cutting. Indian Forester, v.127, n.7, p.827-8, 2001.

ALVARENGA, L.R.; CARVALHO, V.D. Uso de substâncias promotoras de enraizamento de estacas frutíferas. Informe Agropecuário, v.9, n.101, p.47-55, 1983.

BACKES, P.; IRGANG, B. Árvores cultivadas no Sul do Brasil: guia de identificação e interesse paisagístico das principais espécies exóticas. Porto Alegre: Editora Paisagem do Sul, 2004. p.46-7.

BORGES JUNIOR, N.; MARTINS-CORDER, M.P. Efeito do ácido indol butírico no enraizamento de estacas de acácia-negra (Acacia mearnsii De Wild.). Revista Árvore, v.26, n.2, p.223-7, 2002.

CHIANG, C.H. et al. A study of the germination of seed, cutting and characteristics of seedling in Ginkgo biloba L. Quarterly Journal of the Experimental Forest of National Taiwan University, v.10, n.2, p.29-36, 1996. (resumo - texto original em chinês).

DOLE, J.M.; WILKINS, H.F. Floriculture: principles and species. New Jersey: Prentice-Hall, 1999. 613p.

EDMOND, J.B. et al. Fundamentals of horticulture. 4.ed. New York: McGraw-Hill Book Company, 1957. p.197-208. HAMANN, A. Adventitious root formation in cuttings of loblolly pine (Pinus taeda L.): developmental sequence and effects of maturation. Trees, v.12, p.175-80, 1998.

HARTMANN, H.T. et al. Plant propagation: principles and pratices. 7.ed. New Jersey: Prentice Hall, 2002. 880p.

KÄMPF, A.N. Produção comercial de plantas ornamentais. Guaíba: Livraria e Editora Agropecuária, 2000. p.155-8.

KERBAUY, G.B. Fisiologia vegetal. Rio de Janeiro: Guanabara Koogan, 2004. 452p.

MORAES NETO, S.P. et al. Produção de mudas de seis espécies arbóreas, que ocorrem nos domínios da Floresta Atlântica, com diferentes substratos de cultivo e níveis de luminosidade. Revista Árvore, v.25, n.3, p.277-87, 2001.

PIMENTA, A.C. Interações entre reguladores vegetais, épocas do ano e tipos de substrato no enraizamento de estacas caulinares de Sapium glandulatum (Vell.) Pax. 2003. 61p. Dissertação (Mestrado em Agronomia Produção Vegetal) - Setor de Ciências Agrárias, Universidade Federal do Paraná, Curitiba.

REIS, J.M.R. et al. Efeito do estiolamento e do ácido indolbutírico no enraizamento de estacas do portaenxerto Pyrus calleryana Dcne. Ciência Agrotécnica, v.24, n.4, p.931-8, 2000.

VALMORBIDA, J.; LESSA, A.O. Enraizamento de estacas de Ginkgo biloba tratadas com ácido 3-indolbutírico e ácido bórico. Horticultura Brasileira, v.23, supl, p.514, 2005.

WENDLING, I. et al. Substratos, adubação e irrigação na produção de mudas. (Coleção Jardinagem e Paisagismo. Série Produção de Mudas Ornamentais). Viçosa: Aprenda Fácil Editora, 2002, v.2., 165p. 